\title{
ANÁLISE DA INFLUÊNCIA DA FACULDADE UnB PLANALTINA NA COMUNIDADE LOCAL POR MEIO DA EXTENSÃO UNIVERSITÁRIA
}

\section{ANALYSIS OF THE UnB PLANALTINA FACULTY INFLUENCE ON THE LOCAL COMMUNITY THROUGH UNIVERSITY OUTREACH PROJECTS}

\author{
Bárbara Letícia Rodrigues Gomes* \\ ORCID: https://orcid.org/0000-0002-3381-0400 \\ Elaine Nolasco** \\ ORCID: https://orcid.org/0000-0002-1202-6510
}

\section{Resumo}

As políticas de expansão do acesso à educação superior pública no Brasil possibilitaram novas formas de relação entre comunidade acadêmica e os contextos urbanos em que novos campi foram inseridos. O objetivo deste estudo é analisar a atuação da Faculdade UnB Planaltina (FUP) no desenvolvimento da comunidade local, por meio da Extensão, na percepção dos coordenadores de projetos. $\mathrm{O}$ estudo realizado tem caráter qualitativo, exploratório e descritivo, baseando-se em pesquisa documental nos projetos de extensão existentes na FUP e em entrevistas semiestruturadas com os coordenadores dos projetos de extensão selecionados para a pesquisa. Como resultado, constatou-se que a Extensão exerce um papel importante na FUP, aproximando a Universidade da comunidade, mas que precisa de mais espaço institucional e aporte financeiro. Conclui-se que o surgimento da FUP se mostra positivo para a comunidade, estando ainda em momento de adaptação e identificação, mas que sua atuação precisa ser cada vez mais ampliada e estruturada.

Palavras-chave: Universidade. Expansão universitária. Democratização da educação. Reuni. Faculdade UnB Planaltina. Extensão universitária.

\begin{abstract}
Policies for expanding access to public higher education in Brazil have enabled new forms of relationship between the academic community and the urban contexts in which new campuses have been inserted. The aim of this study is to analyze the role of the Faculty UnB Planaltina (FUP) in the development of the local community, through outreach projects, according to the project coordinators' perception. This study has a qualitative, exploratory and descriptive character, based on document research in the existing outreach projects at FUP and on semi-structured interviews with the coordinators of the outreach projects selected for the research. Our results pointed out university outreach projects play an important role in FUP, bringing the University closer to the community. However, they still need more institutional space and financial support. These results led to the conclusion that although the existence of that university is positive for the community, and that it is still in a phase of adaptation and identification. its action needs to be increasingly expanded and structured.
\end{abstract}

Keywords: University. University outreach projects. Democratization of education. Reuni. Planaltina College. University Outreach.

Data recebimento: $30 / 06 / 2021$

Data de aceite: $17 / 09 / 2021$
* Mestrado. Universidade de Brasília (UnB), Brasília - DF, Brasil. E-mail: barbaraleticia@bce.unb.br

** Professora da Universidade de Brasília (UnB), Brasília - DF, Brasil. E-mail: enolasco@unb.br 


\section{Introdução}

Com a globalização, o desenvolvimento técnico-científico das últimas décadas e o sistema capitalista predominante, a obtenção de conhecimento e a cobrança por padrões educacionais nos países são cada vez maiores. No início dos anos 1990, organizações internacionais como o Banco Mundial (BM), Organização das Nações Unidas para a Educação, Ciência e Cultura (UNESCO) e Organização para a Cooperação e Desenvolvimento Econômico (OCDE) publicaram documentos, a partir de estudos prévios, que diagnosticavam e/ou propunham orientações aos países, principalmente os países em desenvolvimento, para que revisassem seus investimentos e métodos/metodologias adotados para a promoção da educação superior.

No Brasil, comumente, a educação é tida como uma questão em segundo plano, somente com a pressão dos organismos internacionais viram-se alguns encaminhamentos para a umdança. "As políticas públicas na área de educação predominantes no Brasil, via de regra, aprofundaram o caráter excludente de seu sistema nacional de educação superior, reproduzindo uma realidade que privilegiava as elites e excluía grupos sociais desfavorecidos" (SANTOS; TAVARES, 2016). Internamente, entidades nacionais da área da educação superior também começaram a debater e a pressionar o governo para a reformulação do ensino superior no Brasil. Dentre elas, se destacaram: a Associação Nacional dos Dirigentes das Instituições Federais de Ensino Superior (ANDIFES) - Proposta de Expansão e Modernização do Sistema Público Federal de Ensino Superior, 2003; o Sindicato Nacional dos Docentes das Instituições de Ensino Superior (ANDES-SN) e a União Nacional dos Estudantes (UNE).

No contexto de expansão da educação superior, surge o Programa de Apoio a Planos de Reestruturação e Expansão das Universidades Federais Brasileiras (Reuni), em 24 de abril de 2007. A idealização do Reuni altera paradigmas sensíveis na estrutura administrativa das Instituições Federais de Ensino Superior (IFES) que aderiram ao Programa. A autonomia universitária, observada sob os vieses político e econômico, é mitigada, pois há interferência estatal na sua capacidade decisória, bem como na gestão de seus recursos (OLIVEIRA, 2013).

Em 2007, a UnB aderiu ao Reuni, foram criados os campi de Ceilândia e Gama, o campus de Planaltina já existia, foi criado na primeira etapa do Plano de Expansão do Ensino Superior do Governo Federal, e novas vagas nos quatro campi da UnB, bem como novos cursos de graduação, no período compreendido entre 2008 e 2012, nos turnos diurno e noturno. O surgimento da Faculdade UnB Planaltina (FUP) teve como objetivo atender à demanda da população do Distrito Federal (DF) e entorno, por oportunidades de acesso à educação superior pública e permitir que a UnB assumisse o papel de aceleração do processo de desenvolvimento socioeconômico e científico da região (BIZERRIL; GUERROUÉ, 2012), trazendo também a possibilidade de desenvolvimento para a comunidade local e para o entorno. De maneira geral, os novos campi abrem possibilidades para a experimentação de novos arranjos de cooperação com a sociedade, projetos inovadores e programas de extensão temáticos ou regionais (ELS; DINIZ; COSTA, 2014). 
Nesse sentido, dentre as três funções universitárias - ensino, pesquisa e extensão - é a extensão a função mais recente. Têm aumentado os estudos dedicados a investigar e avaliar a prática das ações extensionistas e suas consequências (SILVA; DEBOÇÃ, 2017; PIETROVSKI et al., 2018), tanto no que se refere aos aspectos de sua integração com os processos acadêmicos quanto aqueles que a legitimam frente às demandas sociais.

A importância da Extensão para a FUP na inserção regional é destacada por Nogueira, Saraiva e Diniz (2012, p. 60), que afirmam que "a quantidade e diversidade de projetos de extensão desenvolvidos no campus apontam para um diferencial promissor, marcado por um maior engajamento da universidade nas questões locais." Ao abordar o tema de expansão do ensino superior e o impacto causado pelas Universidades, busca-se analisar a atuação da Faculdade UnB Planaltina no desenvolvimento da comunidade local, por meio da Extensão, na percepção dos coordenadores de projetos.

\section{O Programa de Apoio a Planos de Reestruturação e Expansão das Universidades Federais (Reuni)}

O Reuni foi instituído pelo Decreto n ${ }^{\circ} 6.096$ em 24 de abril de 2007, contextualizado no Plano de Desenvolvimento da Educação (PDE), política educacional do governo, que faz parte do Plano de Aceleração do Crescimento (PAC). Tem como objetivos: criar condições para a ampliação do acesso e permanência dos estudantes na graduação; aumentar a qualidade dos cursos; melhorar o aproveitamento da estrutura física e de recursos humanos existentes nas universidades federais; e estimular a diversidade do sistema de Ensino Superior (BRASIL, 2007).

A concepção do Reuni está diretamente ligada ao Plano de Desenvolvimento da Educação (PDE), um programa que visa expandir a atuação das universidades públicas, juntamente com a ampliação de vagas no ensino superior público. A proposta de financiamento da expansão proposta no Reuni viria de fontes do Ministério da Educação e Cultura (MEC), de acordo com o plano elaborado por cada universidade. As unidades escolhiam participar ou não e muitas delas ficavam rodeadas de incerteza e expectativa, pois cada uma, até que recebesse o recurso, teria que dar conta de iniciar o processo de expansão com o que tinha, ou seja, com a mesma estrutura administrativa e financeira, talvez por isso o programa até hoje divide opiniões.

O Reuni foi concluído em 2012 e trouxe mudanças de ordens diversas para as instituições integrantes, tais como de infraestrutura, financeira e cultural. Novas universidades públicas foram implantadas e consolidadas, além de realizada a expansão de novos campi nas universidades públicas existentes, por meio dele. O programa trouxe para as universidades a estrutura multicampi, nos casos em que a instituições já possuía vários campi o Reuni foi determinante para a viabilidade financeira destes (BIZERRIL, 2018).

A partir dessas opiniões, entende-se que o Reuni tenha alcançado suas metas iniciais, mesmo com alguns problemas, a expansão e a democratização da educação no Brasil são perceptíveis com diversos dados que comprovam. 


\section{Impacto de Novos campi}

Com a expansão universitária e a interiorização regional com os novos campi, houve uma mudança no panorama do ensino superior no Brasil. São diversas as modificações percebidas nas regiões onde eles foram instalados. Mudanças tanto no ambiente físico e social foram geradas, impactando nas cidades e em seus moradores, pois a universidade colabora ativamente para o progresso material, a melhoria da qualidade de vida e o ambiente cultural que está inserida, devido ao conhecimento que produz e propaga através das pessoas que forma.

Com a chegada de todo o aparato que é necessário para o funcionamento de um campus universitário, tais como infraestrutura, pessoal e serviços, uma cidade pode ter sua vida modificada. A movimentação de recursos financeiros por meio do pagamento de salários de professores e de funcionários; investimento em obras e equipamentos, das demais despesas de custeio e dos gastos dos alunos oriundos de outras cidades constituem um conjunto de fatores que podem exercer um efeito dinâmico e multiplicador sobre várias atividades das cidades onde as universidades estão inseridas (LOPES, 2003).

Para Hoff et al. (2012), as universidades podem gerar duplo ganho, pois ampliam-se as relações econômicas no entorno da universidade, e ocorrem, no longo prazo, mudanças culturais na região. Os autores citam que primeiro ganho são os impactos diretos e observáveis no curto prazo, principalmente pela movimentação financeira que geram, por conta do consumo de diversos bens e serviços, principalmente pelo aluno e pela emergência de relações comerciais da instituição de ensino com organizações regionais; enquanto o segundo são os impactos indiretos e observáveis no longo prazo, estando relacionados com a capacidade de influenciar o ambiente cultural e o ambiente empresarial da região de inserção. Este ganho ocorre em função do papel formador da universidade e da ampliação de suas atividades fins (ensino, pesquisa e extensão), os quais acabam por influir na cultura do entorno.

Diniz e Vieira (2015) corroboram a afirmação de que as atividades promovidas pelas instituições geram efeitos positivos e as classificam em: quantitativo imediato - impactos positivos sobre a renda e o emprego local; e qualitativa estrutural de longo prazo - recursos humanos de elevada qualificação técnica e acadêmica, aplicação e difusão do conhecimento científico e tecnológico, e infraestrutura de pesquisa, acadêmica e cultural. Os equipamentos das instituições de ensino, como a biblioteca, operam nesse sentido, construindo um ambiente local favorável à geração e difusão de conhecimento e cultura.

O conhecimento gerado pelas universidades passou a transbordar para além das salas de aula, através de ações como pesquisas científicas, extensão universitária, bem como liberação de capital humano, envolvendo-se de forma interativa com a sociedade onde está inserida. A troca de conhecimentos entre a universidade e sociedade resulta em impactos indiretos na dinâmica local. 


\section{A Extensão Universitária}

A partir do princípio de indissociabilidade entre ensino, pesquisa e extensão, a formação universitária se mostra deslocada da realidade social. Com relação à relevância social da universidade, se estabelece a necessidade de engajar comunidade e universidade para que, seja possível a elaboração de políticas públicas que impactem positivamente a sociedade e a universidade seja, portanto, capaz de gerar transformação social. A extensão universitária é aqui entendida como uma "via de mão dupla" (entre sociedade e conhecimento acadêmico). É concebida como processo educativo, cultural e científico que articula o ensino e a pesquisa de forma indissociável e viabiliza a relação transformadora entre universidade e sociedade (TAVARES, 2001, p. 77).

Realizar a interação necessária entre educação e realidade ou universidade e comunidade é, assim, indispensável para viabilizar a construção de conhecimento adequado à realidade social, bem como para produzir ensino e pesquisa capazes de gerarem impacto social e transformação. Pietrovski et al. (2018, p. 17) entendem que

a aprendizagem pautada no pensamento crítico e o importante papel da universidade como um agente do desenvolvimento, articulado os agentes locais e a superação das restrições tecnológicas, econômicas e sociais das realidades regionais onde está inserida. Esse é, portanto, o papel da extensão universitária.

Os objetivos da extensão, conforme orienta Freire (1983, p. 13), não podem ser reduzidos à ideia de estender à sociedade um conhecimento preestabelecido. Para ele, há de se questionar até mesmo o conceito por trás da palavra "extensão", pois esclarece que o saber acadêmico não deve se estender à sociedade, mas se constituir na relação dialógica com ela. A ideia contida nas entrelinhas do vocábulo "extensão" seria a de iluminar, esclarecer, orientar e até normalizar uma outra parte do mundo, o outro, para torná-lo semelhante a si mesmo, ou seja, "domesticá-lo".

A extensão se configura, assim, como canal para a escuta qualificada da comunidade e, dessa forma, para que a universidade, como principal produtora de conhecimento e pesquisa voltadas para a elaboração de políticas públicas, consiga compreender quais são os anseios e necessidades dos reais demandantes das ações do poder público.

Apesar do reconhecimento da importância do seu papel, como um instrumento necessário para que o produto da universidade, a pesquisa e o ensino, estejam articulados entre si e possa ser elevado o mais próximo possível das aplicações úteis na sociedade, a extensão ainda enfrenta dificuldades em se colocar como pilar efetivo da universidade. 


\section{Metodologia}

Esta pesquisa tem abordagem qualitativa, uma vez que possui o objetivo de investigar a atuação da FUP na comunidade, sob a perspectiva da extensão. Como estratégia de invéstigação, foi aplicado o estudo de caso. Quanto à natureza, a pesquisa pode ser classificada como exploratória e descritiva. As técnicas de pesquisa utilizadas foram análise documental e entrevista semiestruturada. O artigo é oriundo de uma dissertação de mestrado com o mesmo título deste artigo, apresentada ao Programa de Pós-Graduação em Gestão Pública da UnB.

\section{Caracterização do objeto de estudo}

No caso desta pesquisa sobre a FUP, se mostra importante entender a história da cidade de Planaltina e o contexto em que a faculdade se inseriu.

\section{Caracterização da Região Administrativa de Planaltina}

A cidade de Planaltina, atualmente integrando o que se denomina Região Administrativa (RA) do DF, equivalente a bairros nas cidades tradicionais do país, possui algumas características peculiares, em relação às demais RAs, pelo fato de ela preexistir à fundação da capital federal. Em seus arredores foi lançada, em 1922, a "Pedra Fundamental" da futura capital. Com a inauguração de Brasília, 21 de abril de 1960, Planaltina passou a fazer parte do DF, antes pertencia ao estado de Goiás, sem mudar a sua denominação, mas perdendo sua autonomia política.

Atualmente, Planaltina é uma das maiores regiões administrativas do DF, com uma população de aproximadamente 189.412 habitantes; teve, nos últimos 25 anos, um crescimento demográfico aumentado, motivado pelo parcelamento e ocupação irregular de terras (BRASIL, 2019). Planaltina possui uma população predominantemente urbana e com baixa densidade demográfica, integrando a área da Região Integrada de Desenvolvimento do Entorno (RIDE). O entorno dessa cidade teve elevadas taxas de crescimento populacional no período compreendido entre 1996-2000, o que vem acarretando uma ocupação desordenada do espaço urbano e um aumento da demanda por serviços essenciais (FUB, 2005).

Localiza no Planalto Central do Brasil, abrange uma área $1.537,16 \mathrm{Km}^{2}$, possui uma economia agrícola e empreendimentos voltados ao setor primário da economia, tendo, ainda de uma forma tímida, atividades voltadas ao setor de serviços e atividades industriais. Porém, apresenta uma das mais baixas rendas per capitas do DF (BRASIL, 2019). 


\section{Faculdade UnB Planaltina}

A FUP é um dos quatro campi que compõem a UnB. A FUP foi inaugurada em 16 de maio de 2006, iniciou suas atividades com um corpo docente de 10 professores e 70 alunos matriculados nos cursos de Licenciatura em Ciências Naturais (LCN) e Bacharelado em Gestão do Agronegócio (GEAGRO). Em 2007, foi criado o curso de Licenciatura em Educação do Campo (LEDOC). A UnB aderiu ao novo plano de expansão das universidades federais Reuni, em 19 de outubro de 2007, e então em 2008, foram criados os cursos noturnos de Bacharelado em Gestão Ambiental (GAM) e Licenciatura em Ciências Naturais (SARAIVA; DINIZ, 2012). Até janeiro de 2020 a FUP possuía 125 professores, 48 servidores técnicoadministrativos, 1.206 alunos de graduação, 132 alunos de pós-graduação, além de colaboradores terceirizados para segurança (28), limpeza (11) e restaurante universitário (22).

São seis os programas de pós-graduação em funcionamento: Ciência de Materiais (PPGCIMA), Meio Ambiente e Desenvolvimento Rural (PPGMADER), Ciências Ambientais (PPGCA), Gestão Pública (PPGGP), Gestão Regulação de Recursos Hídricos (ProfÁgua) e Mestrado em Sustentabilidade junto a Povos e Terras Tradicionais (MESPT). São quatro os cursos de graduação oferecidos pela unidade, todos de caráter interdisciplinar: Licenciatura em Ciências Naturais (diurno e noturno), Licenciatura em Educação do Campo, Bacharelado em Gestão Ambiental e Bacharelado em Gestão do Agronegócio. Os cursos atendem a 1.206 estudantes de graduação, 132 estudantes de pós-graduação.

Atualmente, a FUP possui uma estrutura física compreendida por quatro prédios, que abrangem salas de aula, laboratórios, biblioteca, auditórios, salas de professores, setor administrativo, restaurante universitário, quadra de esportes, alojamento estudantil e estacionamentos.

\section{Projetos de extensão selecionados para a pesquisa}

No período da pesquisa, 2019, a FUP possuía 49 programas, projetos e eventos de extensão em vigência. Por questão de tempo, foram escolhidos 15 projetos das duas principais áreas de atuação, que são Educação e Meio-ambiente, os eixos articuladores e agregadores da FUP, que possui dois cursos de licenciatura e dois cursos de bacharelado relacionados às áreas. Levou-se em conta também a abrangência dos projetos, o período de existência, além da participação da comunidade. No Quadro 1 são apresentados os 15 projetos escolhidos e suas respectivas áreas. 
Quadro 1 - Projetos de extensão selecionados.

\begin{tabular}{|c|c|}
\hline PROJETOS & ÁREAS \\
\hline $\begin{array}{c}\text { A Educação Ambiental na implantação da coleta seletiva na Faculdade UnB } \\
\text { Planaltina no Distrito Federal. }\end{array}$ & Educação \\
\hline Educação e Psicologia: mediações possíveis em tempo de inclusão. & Educação \\
\hline Ledoc itinerante: seminários nas escolas e comunidades de inserção. & Educação \\
\hline $\begin{array}{c}\text { Como está o Clima e a Água na Escola: Práticas Pedagógicas da Educação } \\
\text { Ambiental para o Enfrentamento das Mudanças do Clima. }\end{array}$ & Meio Ambiente \\
\hline Tópicos em Lógica e Matemática Financeira. & Educação \\
\hline O Ensino de Ciências e o Desafio da Aproximação Universidade-Escola. & Educação \\
\hline Feira de Organizações e Inovação da FUP/UnB. & Educação \\
\hline Programa de Extensão Kalunga. & Meio Ambiente \\
\hline $\begin{array}{l}\text { Em busca da Emancipação Humana: Educação de Jovens e Adultos na Reforma } \\
\text { Agrária no Noroeste Goiano, Noroeste Mineiro, Distrito Federal e Entorno. }\end{array}$ & Educação \\
\hline Clube de Xadrez da FUP. & Educação \\
\hline EJA na Universidade. & Educação \\
\hline $\begin{array}{c}\text { Resíduos orgânicos originados no campus UnB Planaltina: implantação de um } \\
\text { sistema de compostagem. }\end{array}$ & Meio Ambiente \\
\hline Territorialidade, meio ambiente e sustentabilidade no Assentamento Rio Bonito. & Meio Ambiente \\
\hline EducAção - Cursinho Preparatório. & Educação \\
\hline Educação Ambiental no Parque Recreativo Sucupira Planaltina DF. & Educação \\
\hline
\end{tabular}

Fonte: Elaborado pela autora.

A divisão dos coordenadores de projetos quanto às áreas de conhecimento da FUP apresenta maior quantidade na área Educação e Linguagens - EDU, com 46,6\%, seguido de Ciências da Vida e da Terra - CVT e Ciências Sociais e Humanas - CSH, com 20\% cada. O que corresponde com os eixos escolhidos para entrevistas, que são Educação e Meio-ambiente.

\section{Pesquisa Documental}

Para investigar a formação da comunidade acadêmica do campus da FUP, foram mensurados o quantitativo de colaboradores através do Centro de Informática (CPD), juntamente com o Decanato de Gestão de Pessoas (DGP) e dos estudantes, através do Decanato de Ensino e Graduação (DEG) e Decanato de Pós-graduação (DPG). Dados relativos aos programas, projetos e ações da Política de Assistência Estudantil foram coletados junto à Diretoria de Desenvolvimento Social (DDS). Para a análise da comunidade externa, a FUP, mais especifi- 
camente da Região Administrativa de Planaltina, foram obtidos dados da Pesquisa Distrital por Amostra de Domicílios (PDAD) da Codeplan (Companhia de Planejamento do Distrito Federal). Para as informações relativas à Extensão, foram analisados os dados do Decanato de Extensão (DEX) inseridos no Sistema de Extensão (SIEX), além do contato direto com o colegiado de extensão da FUP.

\section{Entrevistas}

Para analisar as contribuições dos Projetos/Programas de Extensão a comunidade local, foi feito um levantamento descrevendo o direcionamento dos projetos, após a avaliação das informações foram escolhidos 15 projetos dos dois principais eixos, que são Educação e Meios Ambiente, os quais foram avaliados minunciosamente através de entrevistas com seus coordenadores.

Cabe sublinhar que, na entrevista, o roteiro de perguntas permite sondar um assunto ou aprofundá-lo, descrever processos e fluxos, entender o passado, analisar, discutir e fazer prospectivas. E para analisar as entrevistas, considerou-se o emprego da técnica de análise de conteúdo, a qual vem sendo usada com frequência nas pesquisas qualitativas. Em última instância, qualquer técnica de análise de dados significa uma metodologia de interpretação que possui procedimentos peculiares, envolvendo a preparação dos dados para a análise (MOZZATO; GRZYBOVSKI, 2011).

\section{Análise das Informações}

Para a análise e interpretação das informações, optou-se pelo emprego da técnica de análise de conteúdo, desse modo, realizou-se, primeiramente, a transcrição do material coletado a partir das entrevistas. Para esta análise, foram consideradas as seguintes fases: (1) pré-análise; (2) exploração do material; (3) tratamento dos dados, inferência e interpretação. Por fim, procedeu-se à categorização. As categorias nesta pesquisa foram elaboradas $a$ posteriori, definidas e interpretadas cruzando as informações emitidas nas verbalizações dos participantes, nos documentos selecionados e no arcabouço teórico desta pesquisa.

\section{Resultados e discussão}

\section{Diagnóstico socioeconômico da comunidade acadêmica da FUP}

A fim de entender de que forma a FUP conseguiu se integrar à comunidade da cidade de Planaltina e entorno, foi levantado o local de residência dos integrantes da comunidade acadêmica, servidores técnico-administrativos, professores e estudantes. Na Figura 1, é apresentada a localização das moradias dos técnicos-administrativos da FUP. A maioria deles (40\%) mora na cidade em o que o campus está instalado, em Planaltina/DF; outra parcela relevante reside na 
cidade mais próxima, que é Sobradinho. Na parcela outros, se encaixa o restante do grupo, que se encontra fragmentado nas diversas Regiões Administrativas do DF.

Figura 1 - Local de moradia dos técnicos administrativos da FUP.

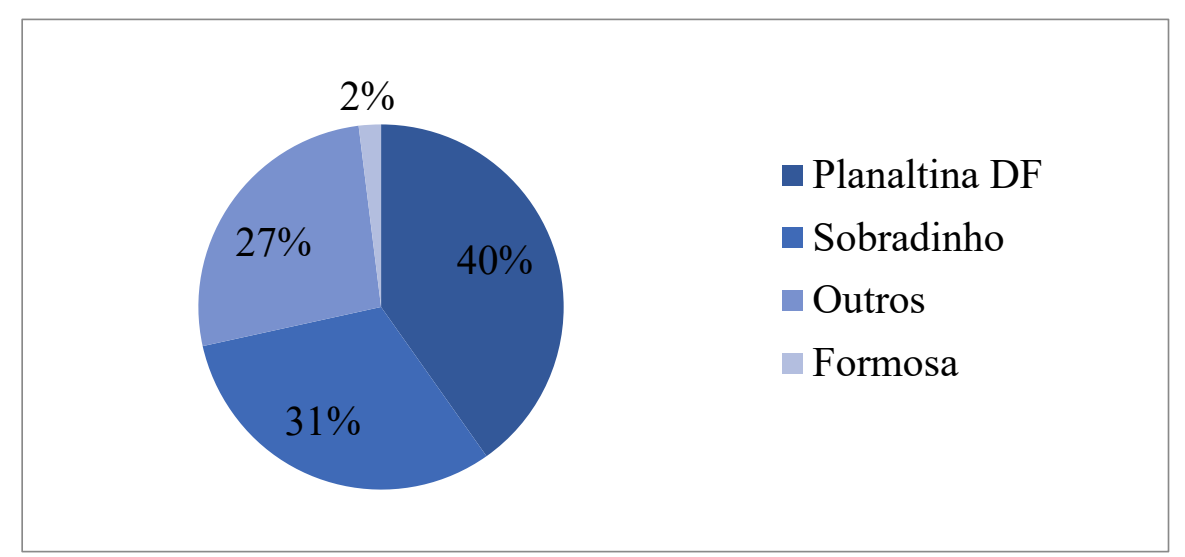

Fonte: CPD /UnB (2019).

Esse resultado demonstra que os servidores técnico-administrativos da Universidade se beneficiaram com o campus da FUP, pois eles têm a oportunidade de trabalhar perto de casa, como demonstram as porcentagens, trazendo ganhos financeiros e de qualidade de vida.

No que tange aos professores, dos 125 no total, a divisão por local de moradia se mostra mais fragmentada, conforme demonstrado na Figura 2. Do total de professores ativos até junho do ano de 2019, 41\% estão na Região Administrativa do Plano Piloto, mais especificamente na Asa Norte. Esse número expressivo se justifica devido ao benefício oferecido pela $\mathrm{UnB}$, de moradia funcional aos servidores técnicos e professores, localizado nessa região.

Figura 2 - Local de moradia dos professores da FUP.

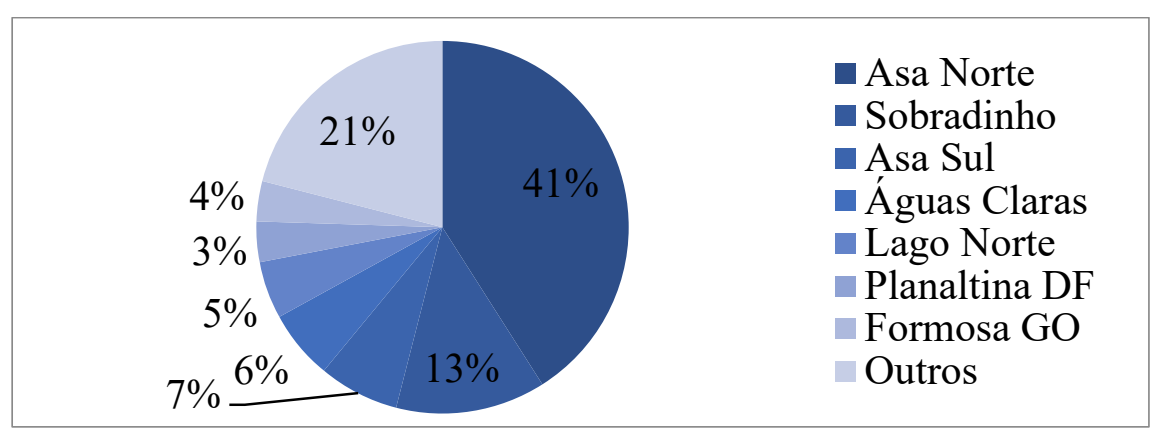

Fonte: CPD /UnB (2019). 
Conforme a Figura 2, a cidade de Sobradinho se destaca, sendo a segunda colocada no quantitativo de professores, e a região de Planaltina fica apenas com $4 \%$ dos professores do campus. Além da questão da moradia funcional, a proximidade das regiões administrativas faz com que o deslocamento não seja tão longo, cerca de $40 \mathrm{~km}$, o que possibilita aos professores ficarem em suas cidades de origem, sem a necessidade de fixar moradia na cidade no qual o campus está inserido. Mas o que não deixa de trazer benefícios socioeconômicos para a cidade, principalmente com relação à alimentação, lazer, combustível entre outros.

Na Figura 3, observa-se que 32\% dos alunos da FUP, entre graduação e pós graduação, são de Planaltina/DF, cidade do campus, seguida de Sobradinho, cidade do DF mais próxima. Ressalta-se que também aqui o considerável quantitativo de estudantes da Universidade, moradores das cidades do estado do Goiás, tais como: Cavalcante e Teresina.

Trata-se de estudantes do curso Licenciatura em Educação no Campo, curso que foi criado com o objetivo de formar educadores para atuar nas escolas de Educação Básica do Campo, com ênfase na construção da Organização Escolar e do Trabalho Pedagógico para os anos finais do Ensino Fundamental e do Ensino Médio. No entanto, um dos requisitos para o ingresso neste curso é ser morador do campo e necessariamente de uma das cidades da região de abrangência do campus.

Destacam-se, também, as cidades de Planaltina/GO e Formosa/GO, ambas fazem divisa com Planaltina/DF, região do campus Planaltina, localizados na região Nordeste do Entorno do DF e possuem quantidade significativa de alunos no campus, 16 e $24 \%$, respectivamente. Tais dados corroboram a concluir que o campus consegue atingir sua área previamente definida como Regiões de Influência do campus UnB, no caso RIC II: campus Universitário UnB Planaltina, abrangendo as Regiões Administrativas de Sobradinho, Planaltina, Brazlândia e Sobradinho II e os municípios de Formosa, Buritis, Cabeceiras, Planaltina de Goiás, Vila Boa e Água Fria de Goiás.

Figura 3 - Local de moradia dos estudantes da FUP.

\begin{tabular}{|c|c|}
\hline 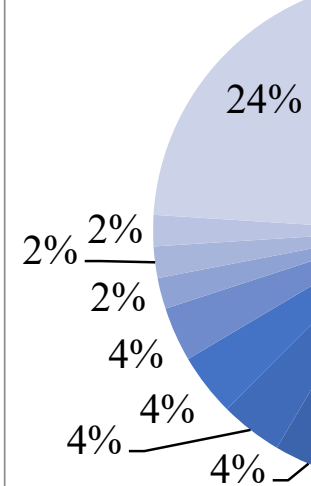 & $\begin{array}{l}\square \text { Planaltina DF } \\
\text { Sobradinho } \\
\text { Cavalcante GO } \\
\text { Teresina GO } \\
\text { Asa Norte } \\
\text { Flores GO } \\
\text { Formosa GO } \\
\text { Planaltina GO } \\
\text { Asa Sul } \\
\text { Paranoá } \\
\text { Outros }\end{array}$ \\
\hline
\end{tabular}

Fonte: CPD /UnB (2019). 
Conforme os dados apresentados na Figura 3, a criação do campus de Planaltina beneficiou, principalmente os servidores técnico-administrativos, que puderam trabalhar em seu local de moradia ou mais perto dele, impactando sua qualidade de vida e seu desempenho no serviço. E para os estudantes que viram uma oportunidade de se inserir na vida acadêmica, vendo a Universidade não mais como um sonho distante, mas como uma realidade. Além da comunidade que também é beneficiada de diversas formas.

Observa-se, a partir dos dados apresentados, a importância da expansão do ensino superior. É inegável o papel do Reuni para o desenvolvimento da universidade pública, melhorando sua estrutura técnica e de pessoal; criação de mais universidades; criação de novos campi interiorização das universidades, que antes se concentravam apenas nos grandes centros; oportunidade de mais vagas. Oliveira (2013) afirma que a expansão da Universidade traz enormes vantagens para a população de cada região, porquanto se adapta a cada realidade e permite o ingresso mais facilitado de alunos que residem próximo a cada campus, pois com o número de vagas disponíveis em cursos desejados, não há razão para migrar para outras localidades.

Bizerril e Guerroué (2012) complementam afirmando o quão importante é o papel social da Universidade. A implantação da FUP está mudando as expectativas dos jovens e de toda a comunidade. A FUP estabeleceu um importante diálogo com a sociedade em um importante troca de conhecimentos, o campus de Planaltina oferece atualmente aos jovens a expectativa de uma formação superior, aos pais a esperança de um futuro para seus filhos, e à comunidade a certeza da presença de um forte parceiro para promover o desenvolvimento local.

\section{Panorama econômico dos estudantes}

O campus de Planaltina, por estar numa região periférica do DF, possui algumas peculiaridades no que diz respeito à situação econômica de seus estudantes. Na sua inauguração, o campus não contava com um Restaurante Universitário, nem com um alojamento para os alunos do curso da Educação do Campo, que estudam em modelo de alternância. A partir disso, a Direção do campus viu a necessidade de pagamento em pecúnia da bolsa alimentação e também o aluguel de uma residência provisória. Conforme demonstrado na Tabela 2, estes são os gastos com os programas, projetos e ações da Política de Assistência Estudantil desenvolvidas na UnB, por meio da Diretoria de Desenvolvimento Social (DDS), mais precisamente na FUP. 
Tabela 2 - Gastos com os programas política de assistência estudantil da FUP.

\begin{tabular}{ccccccc}
\hline $\begin{array}{c}\text { Programas da } \\
\text { DDS }\end{array}$ & Estudantes & R $\$$ & Estudantes & R $\$$ & Estudantes & R $\$$ \\
\hline Alimentação & - & - & - & - & - & - \\
Moradia & 148 & $805.138,38$ & 203 & $1.005 .940,00$ & 168 & $924.850,00$ \\
PAS & 425 & $2.026 .005,00$ & 445 & $1.812 .570,00$ & 399 & $1.729 .335,00$ \\
Creche & - & - & 6 & 5.520 & 11 & 38.550 \\
Transporte & - & - & 4 & 3.600 & 9 & 17.700 \\
\hline TOTAL & - & $2.831 .143,38$ & - & $2.827 .630,00$ & - & $2.710 .435,00$ \\
\hline
\end{tabular}

Fonte: DDS (2019).

Conforme os dados apresentados na Tabela 2, o auxílio moradia abrange uma quantidade considerável de alunos, mas destaca-se principalmente o Programa de Auxílio Socioeconômico, levando-se em conta um total de cerca de 1.300 alunos já beneficiados. Observa-se que um terço dos alunos precisam de algum auxílio para se manter na Universidade. Destaca-se essa questão como uma das diretrizes do Reuni, que prevê, em seu artigo $2^{\circ}$ artigo $\mathrm{V}$ - ampliação de políticas de inclusão e assistência estudantil.

\section{Programa Moradia Estudantil}

O Programa Moradia Estudantil - Graduação tem por finalidade facilitar o acesso e a frequência do estudante em situação de vulnerabilidade socioeconômica ao campus universitário, promovendo essa aproximação com moradia ou transporte.

I. Pecúnia: concessão mensal de auxílio financeiro para moradia estudantil e aproximação ao campus, no valor de R $\$ 530$ (quinhentos e trinta reais).

II. Vaga em apartamento na Casa do Estudante Universitário (CEU), voltada exclusivamente para estudantes provenientes do campus Darcy Ribeiro cujas famílias não possuam imóveis nem residência fixa no DF.

III. Auxílio Transporte: concessão mensal de auxílio financeiro para custear parcialmente as despesas do estudante com o transporte interestadual entre sua residência e o campus universitário. A modalidade de Auxílio Transporte é exclusiva para estudantes residentes nas cidades que compõem a Ride-DF. A destinação das vagas para essa modalidade se deve à impossibilidade de acesso integral ao passe livre estudantil da Secretaria de Transporte e Mobilidade.

Conforme demonstrado na Tabela 2, o gasto da FUP com moradia abrange cerca 150 a 200 alunos por ano, que se dividem entre a pecúnia e o auxílio transporte, já que a Casa do Estudante se localiza no campus Darcy Ribeiro e fica inviável para os alunos de Planaltina. 
Além disso, na Faculdade existe um alojamento, idealizado para receber, durante o "Tempo Escola", os estudantes do Curso de Licenciatura em Educação do Campo com capacidade para 100 alunos.

\section{Programa Auxílio Socioeconômico (PAS)}

O maior gasto da FUP com programas de Política de Assistência Estudantil é o PAS, Programa que consiste na concessão mensal de um auxílio financeiro de $\mathrm{R} \$ 465$ (quatrocentos e sessenta e cinco reais), com a finalidade de minimizar as desigualdades sociais entre os estudantes da UnB, contribuir para a permanência e a diplomação dos estudantes em situação de vulnerabilidade socioeconômica matriculados em cursos presenciais de graduação. $\mathrm{O}$ programa tem concedido auxílio para cerca de 400 a 450 estudantes por ano, quantidade que vem em queda desde 2017.

\section{Programa Bolsa Alimentação}

É desenvolvido em parceria com o Restaurante Universitário (RU) e consiste na gratuidade das refeições servidas (café da manhã, almoço e jantar) aos estudantes de graduação e de pós-graduação participantes dos programas de assistência estudantil (PPAES) em todos os campi. A demanda por alimentação dos estudantes PPAES é totalmente atendida pela DAC/ DDS em parceria com a Diretoria do Restaurante Universitário (DRU/DAC) nos quatro campi. Até a resolução do CAD n²7/2018 vigente a partir de 29/06/2018, os grupos eram definidos da seguinte forma: Grupo I: isento (assistência estudantil) fazem parte desse grupo estudantes de graduação e de pós-graduação stricto sensu, participantes do programa de Assistência Estudantil (com renda familiar per capita inferior a 1,5 salário-mínimo. Para esse grupo o subsídio pago pela Universidade de Brasília é de 100\%; Grupo II: R $\$ 1,00$ (estagiários e prépecG); Grupo III: R \$2,50 (estudantes de graduação, pós-graduação e servidores UnB); Grupo IV: R\$13,00 (visitantes almoço e jantar); Grupo V: R\$7,00 (visitantes café da manhã). De acordo com a Tabela 3, o Restaurante Universitário possui uma divisão em cinco grupos, contando atualmente com cinco restaurantes.

A FUP possui a maior quantidade de refeições servidas para pessoas inseridas no grupo I, 74\%, alunos isentos de pagamento, ou seja, aqueles com baixa renda. Comparando com os outros campi, como por exemplo a FCE, $50 \%$ estão no grupo I, ainda assim o dado da FUP, chama atenção. Essa é uma das informações que corroboram na afirmação de que a FUP possui peculiaridades distintas dos outros campi, com necessidades financeiras mais urgentes e um caráter social abrangente. 
Tabela 3 - Número de Refeições servidas no RU por campi em 2018.

\begin{tabular}{ccccccc}
\hline Campi/grupos & Grupo I & Grupo II & Grupo III & Grupo IV & Grupo V & TOTAL \\
\hline Darcy $^{1}$ & 672719 & 350.872 & 633.854 & 5.989 & 359 & 1.663 .793 \\
FUP $^{2}$ & 79.079 & 6.629 & 20.882 & 182 & 22 & 106.794 \\
FGA $^{3}$ & 52.100 & 29.487 & 55.237 & 69 & 9 & 136.902 \\
FCE $^{4}$ & 67.039 & 20.976 & 43.904 & 233 & 18 & 132.170 \\
Fazenda $^{5}$ & 2.950 & 2.371 & 4.769 & 7 & 2 & 10.099 \\
TOTAL & 873.887 & 410.335 & 758.646 & 6.480 & 410 & 2.049 .758 \\
\hline
\end{tabular}

Fonte: RU/UNB (2019).

Legenda: ${ }^{1}$ Darcy - campus Darcy Ribeiro (sede da UnB); ${ }^{2} \mathrm{FUP}$ - Faculdade UnB Planaltina; ${ }^{3} \mathrm{FGA}$ Faculdade UnB Gama; ${ }^{4} \mathrm{FCE}$ - Faculdade UnB Ceilândia; ${ }^{5}$ Fazenda - Fazenda Águas Limpas.

Os programas, projetos e ações da Política de Assistência Estudantil, desenvolvidas na UnB, têm como objetivo a permanência e a formação acadêmica com qualidade para os estudantes em situação de vulnerabilidade socioeconômica na educação superior. Nesse sentido observa-se que todos esses esforços proporcionam a possibilidade de estudantes de locais mais carentes como é o caso da FUP, se inserirem na vida acadêmica, assim como sugerido no Decreto de Criação do Programa Reuni, Decreto n ${ }^{0}$ 6.096, de 24/04/2007, que se propôs, também, a criar mais condições para a ampliação do acesso e permanência na educação superior. Entre as diretrizes esboçadas pelo programa destacam-se: a redução das taxas de evasão, a ocupação de vagas ociosas, o aumento de vagas de ingresso, especialmente no período noturno e a ampliação de políticas de inclusão e assistência estudantil (BRASIL, 2007) tendo como objetivo a redução das taxas de evasão. Dessa forma, entende-se que na FUP o programa alcançou discentes em situação de fragilidade econômica, que caso não existisse o programa, não teriam acesso à universidade pública.

Segundo Santos (2016), para uma permanência qualificada na universidade são necessárias condições materiais que permitam a subsistência. É necessário dinheiro para comprar livros, almoçar, lanchar, pagar o transporte, dentre outros, mas é necessário também o apoio pedagógico, a valorização da autoestima, os referenciais docentes. Os resultados da pesquisa e a literatura apontam que não basta o acesso à educação superior ser ampliado, tendo em vista a realidade vivenciada pelos alunos, em grande parte, proveniente de escolas públicas e, em sua maioria, pretos e pardos. Alves (2010) corrobora dizendo que são necessários mecanismos que possibilitem a esses uma trajetória acadêmica com qualidade, no sentido de vislumbrar melhores condições de estudos. 


\section{Diagnóstico da comunidade local da FUP - Planaltina DF}

Conforme a Pesquisa Distrital por Amostra de Domicílios (PDAD), realizada pela Companhia de Planejamento do DF (Codeplan), a Região Administrativa de Planaltina possui uma taxa de natalidade de média para alta, e uma expectativa de vida que tem aumentado ao longo do tempo, número significativo de jovens em idade escolar, o que indica famílias numerosas. A divisão por sexo possui uma diferença mínima, sendo o sexo feminino a maioria com 51,7\% e o masculino com 48,3\% (CODEPLAN, 2018).

Ainda, de acordo com a Codeplan (2018), a maioria da população de Planaltina/DF se declara como sendo parda $64,4 \%$, seguida de branca $25,4 \%$ e preta $9,6 \%$. Atualmente, a quantidade de pessoas nascidas no DF já supera as nascidas em outros estados, com $58 \%$ contra $42 \%$. A grande maioria da população se declara alfabetizada (95\%). No que tange à escolaridade, $32,7 \%$ possuem o ensino médio completo e $15,1 \%$ o superior completo, chama a atenção o percentual grande de pessoas com o nível fundamental incompleto 32,2 \%, o que denota a necessidade de maior incentivo na Educação de Jovens e Adultos e por consequência o aumento das chances em chegar ao Ensino Superior.

Um comparativo da escolaridade da população antes e depois da Expansão da Universidade de Brasília, a partir da pesquisa realizada pela Codeplan (2018), indica que, no ano de 2004, somente $1,8 \%$ da população de Planaltina tinha o Ensino Superior Completo. Mestrado e Doutorado apresentam um valor tão ínfimo que estão zerados em valores relativos. Comparado com os dados da última pesquisa de 2018 , o ensino superior completo corresponde a $15,1 \%$ e o incompleto $4,4 \%$ da população, constata-se então um aumento de cerca de 8 vezes no quantitativo de pessoas com nível superior.

Acredita-se que a FUP seja uma das responsáveis por ter contribuído para elevar significativamente a porcentagem de pessoas com nível superior, pois atualmente possui 1.357 alunos egresso formados. Por outro lado, devido ao aumento significativo de faculdades particulares na cidade e de programas como FIES e PROUNI, essas iniciativas também podem ter contribuído para esses valores.

Ainda assim, a instalação da FUP trouxe uma grande contribuição e inovação para a cidade de Planaltina - DF e para área de influência, tais como: aumento de oportunidades para o acesso ao ensino superior e formação de mão de obra para o mercado de trabalho e desenvolvimento social da região. Segundo Nogueira, Saraiva e Diniz (2012), os cursos da FUP podem ser considerados inovadores, pois possuem foco, abordagem metodológica e grades curriculares multidisciplinares, possibilitando um leque maior de atuação dos egressos no mercado de trabalho.

Com relação ao mercado de trabalho em Planaltina, a maioria dos moradores da cidade trabalha na própria RA, 41,3\%,37,3\% exercem sua profissão no Plano Piloto e 21,3\% em outras localidades. O setor de atividades pode assim ser distribuído, Serviços, 69,3\%, seguido por Comércio 20,7\% e Industria 8,5\%. Parcela significativa trabalha no serviço formal, sendo que $60,3 \%$ se definem como empregado. São autônomos ou trabalham por conta própria cerca 
de $22 \%$ dos moradores da cidade, o que converge com a porcentagem do setor de comércio, que é onde se encontra a maioria das pessoas que trabalham na informalidade (CODEPLAN, 2018).

\section{Análise dos projetos de extensão da FUP}

Os resultados das entrevistas com os coordenadores dos 15 projetos de extensão selecionados para análise foram apresentados anteriormente no Quadro 1. A fim de organizar o conteúdo de forma simples e cadenciada, dividiu-se a análise dos projetos - por meio das entrevistas realizadas, em cinco seções: I -Motivação para desenvolvimento do projeto; II Público-alvo; III- Benefícios do projeto para o público-alvo; VI- Dificuldades do Projeto; VSugestões, a fim de contribuir para o melhor aproveitamento da Extensão na Universidade.

Categoria I, como questionamento inicial da entrevista, procurou-se entender qual a motivação para o desenvolvimento de projetos de extensão. Com base no conteúdo das respostas, foram elencadas cinco subcategorias que melhor correspondem com as principais motivações. A questão do processo educativo, e da necessidade de promover novos aprendizados foi destacada. A extensão universitária, como uma possibilidade de aprendizagem, dispõe os sujeitos e processos aprendentes para uma dinâmica educativa. Portanto, o processo educacional, com base na reflexão e na ação extensionista, contribui para uma educação de nível superior, fazendo justiça ao projeto acadêmico das universidades (SIVERES, 2012).

Sobre a questão dos valores sociais, outra subcategoria, os quais estão enraizados nos programas de extensão, Siveres (2012) corrobora afirmando que a extensão contribui na construção de relações mais estreitas entre a universidade e a sociedade, além de compreender que as atividades universitárias - ensino, pesquisa e extensão - não visam somente a preparação de profissionais, mas algo mais amplo como a formação para o exercício da cidadania. Além disso, outro destaque nas entrevistas foi a questão da inclusão social.

A possibilidade de troca de saberes onde existe uma relação entre Universidade e Comunidade também obteve destaque nas respostas obtidas nas entrevistas, principalmente no que diz respeito à integração da comunidade com a Universidade, outra subcategoria em destaque. A convivência entre universitários e comunidade se faz presente no cotidiano das ações, no diálogo constante, na compreensão das dificuldades diárias do outro, no respeito à realidade social encontrada e na interação entre os diversos sujeitos que compõem as ações extensionistas. A comunidade deve ser estimulada a ter uma participação ativa, seja o ciclo de aprender e ensinar, independentemente do tipo de ação desenvolvida no projeto de extensão, a comunidade deve ter voz ativa, participando e propondo (RABEL, 2012; SIVERES, 2012).

A categoria II corresponde ao público-alvo atendido pelos projetos de extensão pesquisados, que podem ser divididos em comunidade interna e externa à FUP. São diversos os públicos beneficiados o que corrobora o pensamento de Rabel (2012, p. 37), que afirma que "pode-se dizer que a extensão integra em sua prática de realidades, experiências e conheci- 
mentos diversos. Pode-se assinalar, portanto, que na ação extensionista, destaca-se como sujeitos desta: acadêmicos, professores e a comunidade em geral".

A relação principalmente com a comunidade externa se insere como uma maneira de mostrar para os estudantes a grande diversidade da sociedade e seu compromisso profissional e até social de chegar a todos os públicos. Além disso, a convivência com o outro se faz importante à medida em que ensina a respeitar as diferenças, a entender as necessidades de pessoas que muitas vezes não possuem acesso aos mínimos sociais, somente através do trabalho em equipe e a partilha de conhecimento em áreas diferenciadas, proporciona maior crescimento profissional de todos os envolvidos.

Sendo assim "o compromisso social é um princípio da extensão universitária ao passo em que impulsiona a capacidade do estudante a integrar a realidade contemporânea e compreendê-la através do público-alvo atendido" (ALMEIDA, 2012).

Com relação ao público beneficiado pelos projetos analisados, apreende-se que todos atuam na comunidade acadêmica, pois são desenvolvidos por professores e estudantes da Faculdade. No que diz respeito à comunidade, somente 4 dos 15 projetos não atuam diretamente na comunidade local: Coleta Seletiva, Feira de Organizações e Inovação da FUP, Clube de xadrez e Resíduos orgânicos originados no campus. Isto não deixa de ter um impacto indireto pois os projetos relacionados à questão do meio-ambiente trazem benefícios para todos ao redor do campus e para a sociedade em geral. Quanto à Feira e ao xadrez, a comunidade também pode ter algum tipo de contato, pois a Faculdade é sempre aberta à comunidade.

A categoria III aponta os benefícios dos projetos de extensão para o público-alvo, sendo os benefícios citados, dentre eles, a questão da mudança de comportamento dos envolvidos nos projetos, o desenvolvimento de competências e a troca de saberes. Corroborando Freitas (2012), que diz que a extensão universitária é uma importante contribuição na aprendizagem acadêmica, na formação cidadã, na qualificação profissional, na conduta ética e transformadora do indivíduo e da sociedade, sendo considerada pelos acadêmicos como um diferencial na formação pessoal e acadêmica.

O diálogo com a comunidade de maneira mais efetiva, juntamente com a vivência em sociedade e experiência prática, também foram narrativas constantes nas entrevistas. Assim, a extensão universitária, pelas características apresentadas, tem possibilidade de se concretizar como uma prática acadêmica essencial. Freitas (2012) acrescenta dizendo que a Extensão se coloca como um espaço estratégico para promover práticas integradas entre várias áreas do conhecimento, favorecer a multidisciplinaridade, potencializar o desenvolvimento de uma consciência cidadã e humana e, assim, a formação de sujeitos de mudança, capazes de se colocarem no mundo com uma postura mais ativa e crítica. A extensão trabalha no sentido de transformação social.

Por meio dos projetos, se torna possível o aumento da visibilidade da FUP para a comunidade, ampliando o diálogo com os diversos atores sociais, possibilitando parcerias com as diversas instituições existentes, gerando, então, uma ação multiplicadora dos possíveis benefícios da Universidade para a comunidade em que está inserida. Nesse sentido, entende-se 
que os saberes por ela produzidos não podem permanecer circunscritos ao espaço acadêmico, fechados entre os muros que a rodeiam. Espera-se que os saberes se constituam em mecanismo por meio do qual a universidade se faz presente na vida da cidade, contribuindo para instrumentalizar a luta por transformações sociais (PAIVA; SARAIVA, 2011).

Formar cidadãos críticos e que tenham capacidade de reflexão das situações que o cercam foi outra questão recorrente nas respostas dos entrevistados, além de proporcionar atitude colaborativa e perspectiva emancipadora aos atores evolvidos. Pensar extensão na formação acadêmica e cidadã é pensar em profissionais conscientes e comprometidos com o desenvolvimento social. Nesse sentido, é fundamental a conscientização sobre as questões éticas que envolvam o cotidiano dos acadêmicos, de modo que os atores sociais comprometidos nesse processo possam crescer intelectual, pessoal, social, ética e politicamente. A Universidade deve oferecer uma educação que contribua para a construção da educação integral dos estudantes, como ser humano e cidadão, e a extensão propicia aos alunos mudanças nos seus valores de vida, transformandoos em pessoas mais sensíveis às causas da realidade social. (ALMEIDA, 2012; SÁ, 2012).

A categoria IV corresponde às dificuldades enfrentadas nos Projetos. Devido a problemas estruturais e às diversas crises financeiras e políticas do país, o maior problema enfrentado na concepção dos entrevistados diz respeito à falta de recursos, ou seja, questões financeiras, corroborando o agravamento de outras questões.

Existe a necessidade de se dar ênfase a uma política acadêmica que inclua a extensão, e um tratamento com equidade para o ensino, pesquisa e extensão, as três dimensões da Universidade deveriam ser indissociáveis e equilibradas para que a instituição cumprisse seus fins de modo mais aberto à sociedade.

Silva e Frantz (2002, p. 161) acrescentam dizendo que "a extensão foi atribuída a responsabilidade de produzir as relações entre universidade e a sociedade, como se aquela tivesse obrigação moral de dar respostas aos problemas desta, sem uma estrutura adequada para tal". Ou seja, sem recursos, transporte, material e infraestrutura, a função da extensão fica aquém do esperado. Além disso, os estudantes extensionistas necessitam de algum tipo de apoio e incentivo, principalmente os alunos da FUP, que de acordo com dados do DAC, possuem um perfil extremamente carente. Portanto, acredita-se que um dos motivos para a sua inserção num projeto de extensão é o auxílio financeiro através da bolsa de extensão, que pode vir a colaborar para a permanência desse aluno no ensino superior. Esta dificuldade foi bastante citada pelos coordenadores, que se veem muitas vezes sozinhos em seus projetos por não terem possibilidade de ofertar bolsas de extensão.

Outra dificuldade citada diz respeito à questão da divulgação dos projetos. "Sugerese uma maior divulgação da extensão na comunidade acadêmica, como forma de proporcionar aos demais alunos a oportunidade de vivenciar e crescer na extensão" (FREITAS; SOUZA; FRANÇA, 2012, p. 119). Além da divulgação interna, salienta-se a necessidade de divulgação externa para toda a comunidade, com o intuito de cumprir seu papel de promover a integração da Universidade com a Sociedade, pois um ponto importante a ser considerado na experiência 
extensionista é que esta pode propiciar, além de um sentimento de pertencimento, um compromisso com as questões societárias pertinentes a seu tempo presente (ALMEIDA, 2012).

Por fim, Neres (2017, p. 49) conclui que "o campus de Planaltina ainda enfrenta problemas com a insuficiência de recursos financeiros, falta de estrutura adequada para as atividades de extensão e necessidade de alocação de recursos humanos para fazer a gestão das atividades de extensão".

A categoria $\mathrm{V}$ corresponde a sugestões e propostas de melhorias a fim de contribuir para as ações de extensão. Ressalta-se que a necessidade de valorização da extensão, bem como a necessidade de maiores investimentos na área, foram sugestões bastante recorrentes nas entrevistas. Isso confirma o a posição de Almeida (2012, p. 75) que "considera que o projeto de extensão deve ser mais valorizado em sua participação na Universidade. Já tarda o momento que este ocupe seu devido lugar ao lado da pesquisa e do ensino".

Faz-se necessário um pensamento mais abrangente e inovador, e para que a extensão seja um espaço de aprendizagem, é necessário que ela se constitua numa manifestação do projeto institucional, por meio de geração e comunicação de conhecimentos significativos (SOUSA; SIQUEIRA, 2012). Ou seja, a Universidade precisa colocar a extensão como um projeto institucional, com mais incentivo às ações. Silva e Frantz (2002) acreditam que a extensão universitária é uma atividade que tende a consolidar-se, como resposta aos desafios colocados à universidade, tanto por aqueles que querem flexibilidade, competição e eficiência, quanto por aqueles que exigem da universidade um caráter mais popular, sendo essencial o seu desenvolvimento.

Por fim, Tremblay (2011) afirma que "a busca da excelência científica não deve ser um álibi para a falta de engajamento social, e com frequência é não mais que ilusão e engodo. Os universitários devem almejar a excelência em sua condição de cidadãos, tanto quanto em seu papel de homens da ciência".

Com base nos contextos investigados, os projetos de extensão da FUP interferem diretamente na realidade da comunidade, que recebe da universidade conhecimentos e informações. Além disso, a extensão é essencial tanto para o aperfeiçoamento dos discentes quanto para o processo de formação continuada dos docentes, para que ambos busquem uma maior integração com os demais setores da sociedade.

Apesar de todos os limites a serem superados (aprofundar a articulação entre as três funções da universidade; buscar viabilizar a parte financeira; maiores articulações com parceiros internos e externos da universidade, bem como aprimorar a formação dos estudantes envolvidos e o aproveitamento do conhecimento produzido), os envolvidos, coordenadores, estu-antes e comunidade se mostram mobilizados com a causa, numa busca constante por mudança social, um dos principais objetivos da extensão. 


\section{Considerações finais}

O programa Reuni trouxe muitas contribuições para a universidade e para a população, ampliando e democratizando o acesso ao ensino superior. Os dados apresentados neste estudo demonstram sucesso da política de expansão de vagas prevista pelo programa no campus de Planaltina, que além de cumprir sua missão institucional, consolida e fortalece a FUP, proporcionando inclusão social em um campus com perfil multidisciplinar.

Destaca-se, ainda, o papel social da universidade, pois a FUP tem mudado as expectativas de toda a comunidade local, estabelecendo um importante diálogo com a sociedade em uma troca de conhecimentos e participação de forma decisiva em temas relevantes locais, além de promover o desenvolvimento.

Foi possível concluir que principalmente os servidores técnico-administrativos e estudantes foram beneficiados com a instalação da FUP, pois a maioria reside na cidade, sendo os docentes em menor quantidade, devido à proximidade das regiões administrativas de origem, tornando desnecessária a mudança. Com as informações da situação econômica dos estudantes, visto que uma grande porcentagem é classificada como carente, as políticas assistências e o campus perto de casa possibilitaram para muitos a oportunidade de ingressar no ensino superior.

Constatou-se que a Extensão exerce um papel fundamental na FUP, aproximando a Universidade da comunidade, trazendo o desenvolvimento de competências, a experiência prática, troca de saberes, além de maior visibilidade para o campus. No entanto, foi possível verificar que a extensão permanece ainda relativamente marginal na programação e na condução das atividades acadêmicas, não tendo uma valorização equitativa ao ensino e à pesquisa, parte porque prevalece uma cultura universitária marcada pelo paradigma da formação e do diploma, e em parte porque é característica das atividades extensionistas serem pouco acadêmicas, formalizada e sistemática, dirigidas para atender demandas variadas.

\section{Referências}

ALMEIDA, L. P. A extensão universitária, processo de aprendizagem do aluno na construção do fazer profissional. In: SIVERES, Luiz (org.). Processos de aprendizagem na extensão universitária. Goiânia: Ed. Puc Goiás, 2012. p. 53-77.

\section{ALVES, E. J. Avaliação do Programa Bolsa Permanência da Universidade Federal do Tocantins, Campus de Palmas. 2010. 195 f. Dissertação (Mestrado Profissional de Avaliação de Políticas Públicas) - Universidade Federal do Ceará, Fortaleza, 2010.}

BIZERRIL, M. X. A.; GUERROUÉ, J. L. L. FUP: a construção coletiva de um campus interdisciplinar. In: DINIZ, J. D. A. S.; SARAIVA, R. C. F. Universidade de Brasília: trajetória da expansão nos 50 anos. Brasília: Decanato de Extensão/UnB, 2012. p. 23-29. 
BIZERRIL, M. X. A. A expansão das universidades federais brasileiras e sua potencial contribuição ao desenvolvimento do país. In: CONFERÊNCIA FORGES, 8., 2018, Lisboa. Anais [...]. Lisboa: Instituto Politécnico de Lisboa, 2018.

BRASIL. Decreto n. ${ }^{\circ}$ 6.096, de 24 de abril de 2007. Institui o Programa de Apoio a Planos de Reestruturação e Expansão das Universidades Federais - REUNI. Diário Oficial da União, Brasília, DF, 24 abr. 2007.

CODEPLAN. Companhia de Planejamento do Distrito Federal. Pesquisa Distrital por amostra de domicílios 2018. Disponível em: http://www.codeplan.df.gov.br/wpcontent/uploads/2019/03/Planaltina.pdf. Acesso em: 18 abr. 2019.

CPD. Universidade de Brasília. Centro de Informática. Relatório de moradia do corpo docente, técnico e discente da UnB. 2019.

DDS. Universidade de Brasília. Diretoria de Desenvolvimento Social. Relatório de gastos com programas de política estudantil. 2019.

DINIZ, C. C.; VIEIRA, D. J. Ensino superior e desigualdades regionais: notas sobre a experiência recente do Brasil. Revista Paranaense de Desenvolvimento, Curitiba, v. 36, n. 129, p. 99-115, jul./dez. 2015. Disponível em:

http://www.ipardes.pr.gov.br/ojs/index.php/revistaparanaense/article/view/767. Acesso em: 13 jun. 2019.

ELS, R. H. V.; DINIZ, J. D. A. S.; COSTA, T. H. G. R. Da inserção à integração regional: o papel da extensão nos novos campi da Universidade de Brasília. ParticipAção, v. 14, p. 57-71, 2014. Disponível em: https://periodicos.unb.br/index.php/participacao/article/view/21307/19655.

Acesso em: 20 jun. 2019.

FREIRE, P. Extensão ou comunicação. 7. ed. Rio de Janeiro: Paz e Terra, 1983.

FREITAS, A. R. Qualificação e experiência profissional. In: SIVERES, L. (org.). Processos de aprendizagem na extensão universitária. Goiânia: Ed. Puc Goiás, 2012. p.113-121.

FUNDAÇÃO UNIVERSIDADE DE BRASÍLIA. MORHY, L. (org.). Plano de expansão da Universidade de Brasília: Campus UnB-Planaltina, Campus UnB-Ceilândia/ Taguatinga, Campus UnB-Gama. Brasília, 2005.

HOFF, D. N.; MESQUITA, D. G.; SOPEÑA, M. B; SAN MARTIN, A. S. Universidades públicas como instrumento de desenvolvimento regional: um estudo de caso sobre a experiência brasileira. In: SILVESTRE, H. C.; ARAÚJO, J. F. (org.). Coletânea em Administração Pública. Lisboa: Escolar Editora, 2012. v. 1, p. 339-370. 
LOPES, R. P. M. Universidade pública e desenvolvimento local: uma abordagem a partir dos gastos da Universidade Estadual do Sudoeste da Bahia. Vitória da Conquista: UESB, 2003.

MOZZATO, A. R.; GRZYBOVSKI, D. Análise de conteúdo como técnica de análise de dados qualitativos no campo da Administração: potencial e desafios. Revista de Administração Contemporânea, v. 15, n. 4, p. 731-747, 2011. Disponível em: https://rac.anpad.org.br/index.php/rac/article/view/874. Acesso em: 10 jul. 2019.

NERES, I. V. A importância da extensão universitária para a integração e adaptação acadêmica. In: SARAIVA, R. C. F.; DINIZ, J. D. A. S.; RABELO, M. C. N. FUP 10 anos: um campus por inteiro. Brasília: FUP - UnB, 2017. p. 48-70.

NOGUEIRA, M. C. R.; SARAIVA, R. C. F.; DINIZ, J. D. A. S. Desafios da democratização e da expansão da universidade brasileira: a experiência da Faculdade UnB Planaltina. In: SARAIVA, R. C. F.; DINIZ, J. D. A. S. (org.). Universidade de Brasília: trajetória da Expansão nos 50 Anos, Brasília, 2012.

OLIVEIRA, H. C. Gastos públicos federais x ensino superior x expansão da Universidade de Brasília - UnB. 2013. vi, 68 f., il. Dissertação (Mestrado em Economia) - Universidade de Brasília, Brasília, 2013.

PAIVA, O. A. F.; SARAIVA, R. C. F. Projeto Educação Ambiental no Parque Sucupira: desafios para a preservação do patrimônio ambiental em Planaltina (Distrito Federal). In: CATALÃO, V. M. L.; LAYRARGUUES, P. P.; ZANETI, I. C. B. B. (org.). Universidade para o século XXI: educação e gestão ambiental na Universidade de Brasília. Brasília: Cidade Gráfica e Editora, 2011. p. 111-120.

PIETROVSKI, E. F. et al. A prática extensionista em uma universidade pública federal. Extensio: Revista Eletrônica de Extensão, Florianópolis, v. 15, n. 29, p. 2-19, ago. 2018. ISSN 18070221. Disponível em: https://periodicos.ufsc.br/index.php/extensio/article/view/18070221.2018v15n29p2. Acesso em: 14 ago. 2019.

RABEL, L. C. Os sujeitos envolvidos no fazer da extensão universitária. In: SIVERES, L. (org.). Processos de aprendizagem na extensão universitária. Goiânia: Ed. PucGoiás, 2012. p. 37-52.

RU/UNB. Universidade de Brasília. Restaurante Universitário. Relatório do quantitativo de refeições. 2019.

SÁ, S. M. Extensão universitária: espaço para construção e aprendizagem da cidadania. In: SIVERES, L. (org.). Processos de aprendizagem na extensão universitária. Goiânia: Ed. Puc Goiás, 2012. p. 123-143. 
SANTOS, E.; TAVARES, M. Desafios históricos da inclusão: características institucionais de duas novas universidades federais brasileiras. Arquivos Analíticos de Políticas Educativas, v. 24, n. 62, maio 2016. Disponível em: https://dialnet.unirioja.es/servlet/ articulo? codigo $=5623067$. Acesso em: 20 ago. 2019.

SARAIVA, R. C. F.; DINIZ, J. D. A. S. (org.). Universidade de Brasília: trajetória da expansão nos 50 anos. Brasília: Universidade de Brasília, 2012. 63 p. ISBN 9788565088053.

SILVA, L. L.; DEBOÇÃ, L. P. Avaliando as práticas extensionistas na Universidade Federal de Viçosa - campus Rio Paranaíba: as diretrizes do Forpproex às percepções dos atores envolvidos. Revista Gestão Universitária na América Latina, v. 11, n. 1, jan. 2018. Disponível em: https://periodicos.ufsc.br/index.php/gual/article/view/19834535.2018v11n1p116/35438. Acesso em: 20 ago. 2019.

SILVA, E. W.; FRANTZ, W. As funções sociais da universidade: o papel da extensão e a questão das comunitárias. Ijuí: Ed. Unijuí, 2002. 248p.

SIVERES, L. Perspectivas de aprendizagem na extensão universitária. In: SIVERES, L. (org.). Processos de aprendizagem na extensão universitária. Goiânia: Ed. Puc Goiás, 2012. p. 15-34.

SOUSA, S. M. G.; SIQUEIRA, R. M. Os sentidos e significados da experiência formativa/ educativa em contextos de extensão universitária. In: SIVERES, L. (org.). Processos de aprendizagem na extensão universitária. Goiânia: Ed. Puc Goiás, 2012. p. 97-110.

TAVARES, M. G. M. Os múltiplos conceitos de extensão. In: FARIA, D. S. Construção conceitual da extensão universitária na América Latina. Brasília: Universidade de Brasília, 2001.

TREMBLAY, G. O engajamento da universidade no desenvolvimento comunitário. In: TREMBLAY, G.; VIEIRA, P. F. O papel da universidade no desenvolvimento local: experiências brasileiras e canadenses. Florianópolis: APD / SECCO, 2011. p. 11-18. 